\title{
Formas profanas. \\ Ensayos de crítica cultural
}

\author{
ELEONORA CRÓQUER PEDRÓN Universidad Simón Bolívar, Venezuela \\ ORCID 0000-0002-0811-6126 \\ ecroquer@usb.ve
}

\section{Resumen}

El presente volumen recoge una experiencia de encuentro, diálogo y elaboración discursiva en torno al análisis crítico y la investigación literaria, artística y cultural sobre América Latina y, en particular, Venezuela, desarrollada en el Centro de Investigaciones Críticas y Socioculturales del Instituto de Altos Estudios de América Latina de la Universidad Simón Bolívar en Caracas, entre los últimos meses de 2015 y los primeros de 2018: «Formas profanas. Laboratorio de crítica cultural». Los trabajos reunidos en este volumen dan cuenta de la heterogeneidad de intereses de quienes integramos esta suerte de pequeño colectivo reunido alrededor del mismo compromiso de hacer de la crítica cultural un acto de responsabilidad intelectual.

Palabras clave: Formas profanas / Laboratorio de crítica cultural / Venezuela / análisis crítico / investigación cultural

\section{Profane forms. Cultural criticisms essays}

Abstract

This volume contains an experience of encounter, dialogue and discursive elaboration around critical analysis and literary, artistic and cultural research on Latin America and, in particular, Venezuela, carried out at the Center for Critical and Sociocultural Research of the Institute of Higher Studies from Latin America at the Universidad Simón Bolívar in Caracas, between the last months of 2015 and the first of 2018: «Formas profanas. Laboratorio de crítica cultural». The works gathered in this volume show the heterogeneity of interests of those who make up this kind of small group gathered around the same commitment to make cultural criticism an act of intellectual responsibility.

Key words: Formas profanas / Laboratorio de crítica cultural / Venezuela / critical analysis / cultural research

Recibido: 11/6/2020. Aceptado: 15/8/2020

Para citar este artículo: Cróquer Pedrón, E. (2020). Formas profanas. Ensayos de crítica cultural. El taco en la brea, 12 (junio-noviembre). Santa Fe, Argentina: UNL. eooo8 DOI: 10.14409/tb.v1i12.9685 
La profanación de lo improfanable es el deber político de la próxima generación.

Giorgio Agamben «Elogio de la profanación»

\section{1.}

Los textos contenidos en el presente número monográfico de la revista El taco en la brea se desprenden de una experiencia de encuentro, diálogo y elaboración discursiva en torno al análisis crítico y la investigación literaria, artística y cultural desarrollada en Venezuela entre los últimos meses de 2015 y los primeros de 2018 - aunque algunos de los que participaron lo hicieron desde otros países_- «Formas profanas. Laboratorio de crítica cultural» fue el nombre que le dimos a esta experiencia, que se fue consolidando como un espacio transdisciplinario de enunciación académica, en los márgenes de la universidad corporativa que el nuevo milenio ha expandido a nivel global, y en medio del progresivo proceso de desmantelamiento de las otroras prestigiosas universidades autónomas en Venezuela que, en los últimos diez años, se ha traducido en su cada vez más precaria supervivencia y el casi agotamiento de sus proyectos intelectuales. En este contexto, se trataba de la iniciativa de un grupo de estudio y acción conceptual del Centro de Investigaciones Críticas y Socioculturales (www.cics-usb.org), del Instituto de Altos Estudios de América Latina (IAEAL) de la Universidad Simón Bolívar en Caracas, gestado entre investigadores de formación avanzada de la Maestría en Literatura Latinoamericana de esta institución y de otros programas doctorales nacionales e internacionales en Ciencias Sociales y en Literatura, pero provenientes de disciplinas diversas: sociología, historia, literatura, arte. Un grupo al que reunía el deseo de explorar nuevas miradas y proposiciones alternativas para el estudio de las formas, imágenes y discursos de la cultura, capaces además de discutir la tensión nunca del todo resuelta entre los lenguajes y los acontecimientos sociales, subjetivos, sexuales y corporales que impulsan los devenires históricos y políticos de su materialidad.

De la mano de Giorgio Agamben, el nombre «Formas profanas», con el que pronto llegaríamos a identificar una manera de asumir el análisis crítico y la investigación literaria, artística y cultural entre el nosotros que comenzábamos a ser, surgió durante nuestras primeras sesiones de trabajo como una respuesta posible a la pregunta por el sentido de la práctica, en un presente atravesado por poderes cada vez más voraces y desmedidos tanto a nivel nacional como en el mundo entero. Y esta inquietud suponía, por supuesto, problematizar lo que de su potencia semiótica y revolucionaria parecía asimismo cautiva por los dispositivos académicos que marcaban la tendencia a la reproducción más o menos burocratizada de sus protocolos y/o a la banalización del compromiso que en otras épocas había justificado sus intervenciones. En un breve ensayo que leímos con detenimiento al respecto, «Elogio de la profanación» (2005), el filósofo italiano concebía la profanación como una manera de restituir la potencia de lo abierto a los objetos y prácticas de lo humano en la cultura, secuestrados por los «dispositivos» a través de los cuales el poder organiza el gobierno de los hombres y la administración de sus modos de existir en común. Y, en este sentido, terminaba confrontándonos con lo que, en su opinión, tendría que ser «el deber político de la próxima generación». Esto es: «arrancar cada vez a los dispositivos - a todo dispositivo - la posibilidad de uso que ellos han capturado» (121). Ese «deber político» le otorgaba un sentido — y una razón para seguir produciéndose - a todo pensamiento verdaderamente dispuesto a involucrarse en la tarea de desmantelar las nuevas formas de sojuzgamiento y control social del poder sobre las subjetividades adormecidas en su trama, a fin de 
"traer a la luz ese "ingobernable" que es a la vez el punto de partida y el punto de origen de toda política» (Agamben, 2011:264), como señalaba el mismo autor en un texto posterior — «Qué es un dispositivo?».

Alrededor de una mesa grande, como aquella que Benjamin imaginaba en «Experiencia y pobreza», para la recomposición creativa de un mundo distinto en las primeras décadas del siglo $\mathrm{XX}$, fue cristalizando entre nosotros la necesidad de un posicionamiento capaz de sostener lo que ya se presentaba como una forma distinta de emprender el análisis crítico y la investigación literaria, artística y cultural: ¿desde dónde hablábamos?, ¿para qué lo hacíamos? Sin desconocer la heterogeneidad de los objetos y problemas que seguíamos desarrollando, entonces, alrededor de esa mesa coincidimos en el interés por lo menor, tal como lo definieran Deleuze y Guattari; es decir, por aquello que, en Venezuela y en América Latina, sigue siendo expresión de una diferencia que pugna por encontrar un lugar de visibilidad y una escucha por venir en la cultura frente a los poderes que cercan y capturan la intensidad de sus manifestaciones. Coincidimos, también, en la responsabilidad frente al presente complejo en el que necesariamente se inscribía cualquier cosa que pudiéramos pensar o formular: el aquí y el ahora de un país que se resquebrajaba capturado por apetencias voraces, pulsiones incontenibles y disputas irreconciliables; el aquí y el ahora de una época que extremaba sus mecanismos de vigilancia y control sobre el cuerpo social desprovisto de sus más básicas garantías. Y coincidimos, finalmente, en una (a)puesta en común por un tipo de crítica cultural, cifrada en su pertinencia frente a esa contemporaneidad disgregante que, por lo demás, tiende a restringir los espacios de diálogo que tanto hacen a la posibilidad de su expresión.

\section{2.}

A lo largo de casi tres años de trabajo sostenido, y desde una perspectiva en la cual tendían a cruzarse y contaminarse la teoría crítica, la filosofía, la semiótica y el psicoanálisis lacaniano con algunas aproximaciones de cierta crítica cultural latinoamericana más bien heterodoxa e inquieta —Josefina Ludmer, Sylvia Molloy, Raúl Antelo, Julio Ramos, Nelly Richard, entre otros-, las singularidades que integraron esta suerte de pequeño colectivo venezolano fueron elaborando sus propios problemas y objetos de indagación y análisis, algunos con mi asesoría y otros con la de colegas como Julio Ramos y Gina Saraceni. Una primera entrega de la labor que entonces adelantábamos se materializó en la participación del grupo «Formas profanas. Laboratorio de crítica cultural» del Centro de Investigaciones Críticas y Socioculturales (CICS-IAEAL) en la III Conferencia CLACSO-Venezuela (Caracas, del 8 al 11 de noviembre de 2016), con una serie de ponencias que luego se publicaron ampliadas en el volumen Pensar desde el sur. Venezuela desde las Ciencias Sociales y Humanidades: interpelaciones y horizontes (2017). Pasado el tiempo, y con la intención manifiesta de dar cuenta, además, de la situación en la que se inscribe su evidente heterogeneidad, aquella entrega se continúa ahora en lo que podría ser pensado como una segunda intervención, posiblemente más sólida y mejor articulada.

Las propuestas de Neller Ochoa — «El lugar de la revuelta: pulperías e insurgencia en Venezuela (1750-1850)»-, Celiner Ascanio — «Formas bajo sospecha: Nanacinder. Vocero de la Colonia Psiquiátrica de Bárbula (1954-1962). Casos y archivos de la escritura)»—y Verónica Álvarez - «Narrativa de las diferencias en la recomposición de un archivo. Por una contrahistoria de la literatura venezolana del siglo $\mathrm{XX}_{\Downarrow}$ — foucaultianamente exploran prácticas y formaciones 
discursivas excéntricas vinculadas a los espacios más o menos periféricos de la pulpería, el hospital psiquiátrico y la literatura venezolana de la primera mitad del siglo XX. Desde una mirada en la que se encuentran la revisión exhaustiva de documentos históricos menores (crónicas de viaje, informes judiciales y ordenanzas reales) y la atención culturalista a las especificidades que atraviesan la historia cultural de América Latina, Neller Ochoa se aproxima a la comprensión de las pulperías («tugurios» en que coincidían el expendio de víveres con el juego y el consumo de alcohol, frecuentados por una gama indócil de subjetividades marginadas) como lugares donde se transgreden las formas coloniales de disciplinamiento y control social de la colonia, al tiempo que se gesta la emergencia de un discurso insurgente distinto al que impulsaría el ideal independentista desde las élites que se reunían en los salones. Entre la arqueología foucaultiana y la semiótica tocada por el psicoanálisis de Barthes y de Kristeva, por su parte, Celiner Ascanio rescata un documento de difícil clasificación (la revista literaria Nanacinder, publicada entre 1954 y 1962 con trabajos literarios de los reclusos del Hospital Psiquiátrico de Bárbula, situado en la ciudad de Valencia, en Venezuela), para explorar a través de los textos allí contenidos y de la propia intervención de algunos psiquiatras inquietos la generación de un discurso "raro», donde la experiencia de la locura se abre camino en la lengua más allá del orden del discurso que regula sus usos. Y a partir de lo que define como una «autoría monstruosa», Verónica Álvarez propone un acercamiento a los discursos literarios y críticos que organizan el panorama de la literatura nacional de la primera mitad del siglo XX en Venezuela, que se concentra en dilucidar las implicaciones estético-ideológicas de una revisión del archivo tendente a repensar la tradición desde esos acontecimientos que pulsan, exceptuados y/o excepcionales, en sus márgenes. Jordi Santiago Flores, a continuación, y con una orientación más abiertamente lacaniana, reflexiona acerca de la «La viveza criolla venezolana contemporánea y su anclaje en la historia», como síntoma del establecimiento perverso de un lazo social fallido en la Venezuela del siglo XX. Para ello revisa lo que a propósito de la viveza criolla formularan tres intelectuales relevantes de la historia cultural del país: Mariano Picón Salas, Arturo Uslar Pietri y José Ignacio Cabrujas.

Más adelante, Valenthina Fuentes explora las relaciones entre palabra, mirada y experiencia, a partir de su lectura de un texto en el que se conjugan la poesía de Gustavo Pereira y los grabados de Gladys Meneses, en la tradición del libro de artista que explorarán algunos escritores y pintores venezolanos de las últimas décadas del siglo XX. Su texto «Agrietar las palabras, inventar el silencio. Una lectura de Poemas de Gustavo Pereira Grabados de Gladys Meneses (1979)» avanza, así, en la proposición de algunas estrategias de aproximación a lo que, sin duda, aparece como un objeto de alta complejidad conceptual, toda vez que abre una zona de múltiples contaminaciones entre la escritura y la imagen. Y Janis Denis, en «Del "insilio" del pensador contemporáneo al escritor expuesto. Una aproximación a Constancia de la lluvia de Ricardo Ramírez Requena», se concentra en la factura transgenérica del extraño libro de este escritor venezolano reciente que, publicado en 2015, oscila entre el testimonio y la fabulación novelesca. La fina lectura de ambas dimensiones del diario — una más próxima a la «verdad» biográfica del autor y otra referida al personaje fabulado de una historia de ciencia ficción-le permiten a Denis distinguir lo que de este texto refiere a la ruina de lo nacional en los últimos veinte años de su historia republicana, y a raíz del ascenso de Hugo Rafael Chávez Frías al poder; lo que refleja del deterioro físico y subjetivo del autor que se autorrepresenta como un sujeto sin lugar y sin otra patria que su distópica escritura; y lo que traduce de una nueva literatura posautónoma. 
Los tres artículos siguientes de Oriele Benavides, Tatiana Rojas y Eleonora Cróquer Pedrón abren la reflexión sobre Venezuela hacia otros problemas y objetos latinoamericanos. A través de su texto «Formas, temas, verbos: encarnaciones de la poesía en Los detectives salvajes, de Roberto Bolaño», Oriele Benavides propone una lectura minuciosa y exhaustiva de la conocida novela del escritor chileno, que se desplaza del problema de la escritura del diario y de la poesía a lo que de esa escritura se incorpora como cuerpo a través de su propia capacidad de ser afectada por la experiencia y de afectar al lector. Por su parte, en «Un tránsito de la sangre al plástico. Lo prostético en las representaciones del deseo de maternidad de Frida Kahlo», Tatiana Rojas cruza su aproximación a lo que considera uno de los cuadros más extraños de la popularísima pintora mexicana, «Yo y mi muñeca» (1937), y las reflexiones de B.P. Preciado acerca de la dimensión suplementaria del género tal como puede ser pensado a partir del «dildo», para demostrar hasta qué punto el deseo de maternidad de Frida Kahlo tiene más que ver con una construcción de la crítica, que con sus maneras de resolver fetichistamente la falta de un hijo o de sublimarla en la imagen de Diego Rivera. Por último, «Desarticulaciones (2010) / En breve cárcel (1981). Entre la escritura y la vida: Sylvia Molloy, las letras contaminadas de una crítica lateral», de mi autoría, explora el anudamiento entre escritura y vida que hace a la escritura contaminada de Sylvia Molloy, a medio camino entre la ficción literaria y la crítica cultural. Por encima de las categorías estancas de crítica y ficción, entre las cuales la vida trama una relación de vasos comunicantes, y más allá del trazo autobiográfico que nunca se sintetiza en una historia testamentaria del sujeto implicado en ella, se trata de identificar en los lugares de ese anudamiento la expresión de una crítica «lateral»: oblicua, marginal, fronteriza. Es decir, la práctica de lectura e intervención intelectual de una autoría excéntrica que cristaliza entre los reveses del ensayo académico y las formas profanas de lo menor.

\section{Referencias}

Agamben, G. (2005). Elogio de la profanación. En Profanaciones. Barcelona: Anagrama.

Agamben, G. (2011). ¿Qué es un dispositivo? Sociológica, (73), 249-264.

Benjamin, W. (1933). Experiencia y pobreza. http://www.archivochile.com

Deleuze, G. y Guattari, F. (1990). Kafka, por una literatura menor. Ciudad de México: Era.

González Broquen, X. y Ruiz, F.J. (Eds.) (2017). Pensar desde el sur. Venezuela desde las Ciencias Sociales y Humanidades: interpelaciones y horizontes. Caracas: IVIC. 